\title{
Assessing the internal consistency of the CARINA data base in the Pacific sector of the Southern Ocean
}

\author{
C. L. Sabine' ${ }^{1}$, M. Hoppema ${ }^{2}$, R. M. Key ${ }^{3}$, B. Tilbrook ${ }^{4}$, S. van Heuven ${ }^{5}$, C. Lo Monaco ${ }^{6}$, N. Metzl ${ }^{6}$, \\ M. Ishiii ${ }^{7}$ A. Murata $^{8}$, and S. Musielewicz ${ }^{1}$ \\ ${ }^{1}$ NOAA Pacific Marine Environmental Laboratory, 7600 Sand Point Way NE, Seattle, WA 98115, USA \\ ${ }^{2}$ Alfred Wegener Institute for Polar and Marine Research, Climate Sciences, Postfach 120161, \\ 27515 Bremerhaven, Germany \\ ${ }^{3}$ Atmospheric and Oceanic Sciences Program, Princeton University, Princeton, NJ 08544, USA \\ ${ }^{4}$ CSIRO Wealth from Oceans Flagship/ACE-CRC, Hobart, Australia \\ ${ }^{5}$ University of Groningen, Department of Ocean Ecosystems, Biological Center, P.O. Box 14, \\ 9750 AA Groningen, The Netherlands \\ ${ }^{6}$ LOCEAN-IPSL, Université Pierre et Marie Curie, Université Paris 6, Paris, France \\ ${ }^{7}$ Geochemical Research Department, Meteorological Research Institute, Tsukuba, 305-0052, Japan \\ ${ }^{8}$ Research Institute for Global Change, Japan Agency for Marine-Earth Science and Technology, 2-15, \\ Yokosuka, Kanagawa, 237-0061, Japan
}

Received: 29 September 2009 - Published in Earth Syst. Sci. Data Discuss.: 11 November 2009

Revised: 1 July 2010 - Accepted: 7 July 2010 - Published: 22 July 2010

\begin{abstract}
The CARINA project is aimed at gathering and providing secondary quality control checks on carbon and carbon-relevant hydrographic and geochemical data from cruises all across the Atlantic, Arctic and Southern Ocean. In total the project gathered 188 cruises that were not previously available to the public. Of these 188 cruises, 37 are part of the Southern Ocean. Parameters from the Southern Ocean cruises, including total carbon dioxide $\left(\mathrm{TCO}_{2}\right)$, total alkalinity, oxygen, nitrate, phosphate and silicate, were examined for cruiseto-cruise consistency. $\mathrm{pH}$ and chlorofluorocarbons (CFCs) are also part of the data base, but are not discussed here. This paper focuses on the quality control of the Southern Ocean data from the Pacific sector which consisted of 29 cruises of which 17 were included in a previous synthesis called GLODAP, 11 were new cruises from the CARINA dataset, and one cruise was included in GLODAP but was updated with new data and therefore also included in CARINA. The Pacific sector quality control procedures included crossover analysis between stations and inversion analysis of all crossover data. The GLODAP data were included into the analysis as reference cruises but without applying the GLODAP recommended adjustments so the corrections could be independently verified. The outcome of this effort is an internally consistent, high-quality carbon data set for all cruises, including the reference cruises.
\end{abstract}

\section{Data coverage and parameter measured}

Repository-Reference:

doi:10.3334/CDIAC/otg.CARINA.SO.V1.0

Available at:

http://cdiac.ornl.gov/ftp/oceans/CARINA/CARINA_

Database/CARINA.SO.V1.0/
CARINA project main page:

http://cdiac.ornl.gov/oceans/CARINA/Carina_inv.html Coverage: $30^{\circ} \mathrm{S}-75^{\circ} \mathrm{S} ; 135^{\circ} \mathrm{E}-70^{\circ} \mathrm{W}$

Location Name: Pacific sector of the Southern Ocean Date/Time Start: November 1994

Date/Time End: March 2006

Correspondence to: C. L. Sabine

(chris.sabine@noaa.gov) 


\begin{tabular}{|c|c|c|c|c|}
\hline $\begin{array}{l}\text { Data Product } \\
\text { Parameter }\end{array}$ & $\begin{array}{l}\text { Data Product } \\
\text { Flag Name }\end{array}$ & $\begin{array}{l}\text { Exchange File } \\
\text { Parameter Name }\end{array}$ & $\begin{array}{l}\text { Exchange File } \\
\text { Flag Name }\end{array}$ & Units \\
\hline station & & STANBR & & \\
\hline day & & DATE & & \\
\hline month & & DATE & & \\
\hline year & & DATE & & \\
\hline latitude & & LATITUDE & & decimal degrees \\
\hline $\begin{array}{l}\text { longitude } \\
\text { cruiseno }\end{array}$ & & LONGITUDE & & decimal degrees \\
\hline depth & & & & meters \\
\hline temperature & & CTDTMP & & ${ }^{\circ} \mathrm{C}$ \\
\hline salinity & sf & SALNTY & SALNTY_FLAG_W & \\
\hline pressure & & CTDPRS & & decibars \\
\hline oxygen & of & OXYGEN & OXYGEN_FLAG_W & micomole $\mathrm{kg}^{-1}$ \\
\hline nitrate & no3f & NITRAT & NITRAT_FLAG_W & micomole $\mathrm{kg}^{-1}$ \\
\hline silicate & sif & SILCAT & SILCAT_FLAG_W & micomole $\mathrm{kg}^{-1}$ \\
\hline phosphate & po $4 \mathrm{f}$ & PHSPHT & PHSPHT_FLAG_W & micomole $\mathrm{kg}^{-1}$ \\
\hline tco 2 & tco2f & TCARBN & TCARBN_FLAG_W & micomole $\mathrm{kg}^{-1}$ \\
\hline alk & alkf & ALKALI & ALKALI_FLAG_W & micomole $\mathrm{kg}^{-1}$ \\
\hline
\end{tabular}

Table of parameters relevant for this review. For a list of all properties in the CARINA data base see Key et al. (2010).

\section{Introduction}

The development of a CARINA data base dedicated to carbon-relevant cruise data from the Atlantic Ocean was initiated in 1999 as an informal, unfunded project. It resulted in the assembly of a large collection of useful, previously unavailable data. In 2006, at a meeting in Laugarvatn, Iceland this effort was strongly intensified under the aegis of the EU CARBOOCEAN project and the International Ocean Carbon Coordination Project (IOCCP). It was decided that the CARINA data synthesis effort should be extended to include the Arctic and Southern Ocean because of the exceptionally poor coverage in these areas in previous synthesis efforts and the recent availability of new data sets (Key et al., 2010). Because of the strong zonal structure of the Southern Ocean, it was considered most efficient to include the entire circumpolar ocean in the new synthesis effort.

During a meeting at Iceland a Southern Ocean Carbon Synthesis (SOCS) group was formed, which divided up the synthesis work. This group met three times in Kiel, Germany (March 2007); Delmenhorst, Germany (December 2007); and Paris, France (June 2008) to tune the methodology and evaluate the results. Close contact with the Atlantic and Arctic working groups was maintained throughout the process to ensure that consistent data processing and evaluation was maintained among the groups.

The need for consistent data in a large data base is growing as scientists try to address large-scale issues, not only for observational assessments, but also as a validation for largescale modeling efforts. Moreover, the usefulness of accurate older data for time series is recognized as critical for documenting basin-scale and larger temporal changes. A major previous ocean carbon synthesis effort was called GLODAP: Global Data Analysis Project (Key et al., 2004; Sabine et al., 2005), which primarily evaluated data from the large in- ternational WOCE and JGOFS projects in the 1990s. Coincidently, a very large data base of hydrographic, nutrient and oxygen measurements collected during WOCE cruises combined with pre-WOCE historical data was constructed and quality controlled by Gouretski and Jancke (2001) and Johnson et al. (2001), so that the proposed adjustments could also be applied in GLODAP. The result was the release of a coherent dataset of carbon and related parameters which has been widely used (Key et al., 2004) and from which major results originated, e.g., the oceanic sink of anthropogenic $\mathrm{CO}_{2}$ (Sabine et al., 2004a).

The CARINA project made use of the experience gained through GLODAP by studying the GLODAP reports and publications as well as involving key people involved in that project. The original data that went into the GLODAP analyses were also included in the CARINA analysis. This provided an independent validation of the proposed GLODAP corrections and extended the data coverage in order to obtain enough crossover points for all the new cruises to be evaluated. In contrast to the Atlantic and Arctic groups, it was considered more efficient to divide the work into three specific Southern Ocean regions (the Atlantic, Indian and $\mathrm{Pa}-$ cific), rather than by parameters. This paper presents the quality control analysis performed with CARINA and GLODAP data from the Pacific sector of the Southern Ocean.

\section{The Pacific sector of the Southern Ocean}

The Southern Pacific Ocean dataset refers to data collected during cruises conducted even partially in the South Pacific Ocean (south of $30^{\circ} \mathrm{S}$ ) between $135^{\circ} \mathrm{E}$ and $70^{\circ} \mathrm{W}$ (Fig. 1). The boundaries are shared with the Atlantic and Indian quality control analyses(Hoppema et al., 2009; Lo Monaco et al., 2010). The cruises on the boundaries were evaluated by both regional groups seperately, then compared to determine 


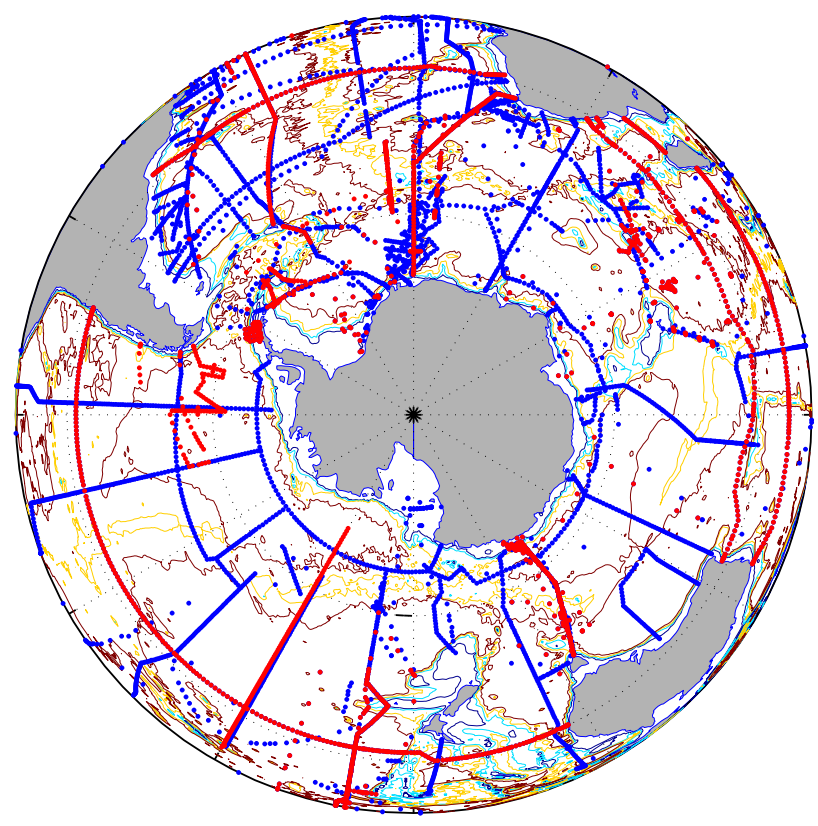

Figure 1. Map of the Southern Ocean with CARINA station positions in red and GLODAP reference cruise stations in blue.

the most appropriate assessment. This approach also helped confirm the consistency of the evaluations by the different regional groups.

This dataset consists of 29 cruises of which 17 were included in the previous GLODAP synthesis (Key et al., 2004) and 11 were new cruises from the CARINA dataset and one cruise 09AR19960822 was included in GLODAP but was updated with new data and therefore also included in CARINA (Table 1). The CLIVAR and Carbon Hydrographic Data Office (CCHDO) provides an online interactive map of Southern Ocean cruises with the common cruise designations that is useful for identifying particular cruise tracks (http://cchdo.ucsd.edu/southern.html). The most frequently studied area in the region is along the SR3 line south of Tasmania along approximately $140^{\circ} \mathrm{E}$. The second most frequently studied area is the P15S line east of New Zealand. Both of these lines are regularly occupied by Australian scientists but other countries have also run cruises in these areas. The only zonal lines that stretch all the way across the Pacific are the $\mathrm{P} 06$ section along $32^{\circ} \mathrm{S}$ at the northern boundary of the Southern Ocean study and S4P along $66^{\circ} \mathrm{S}$. P06 was occupied in 1992, then again in 2003. S4P was only occupied once in 1992. Another zonal line that covered the eastern South Pacific along $\sim 53^{\circ} \mathrm{S}$ was conducted as part of the P17 World Ocean Circulation Experiment (WOCE) cruises in 1992-1993. The lack of zonal cruises relative to other ocean regions means that there are very few crossovers for evaluating the consistency of the Southern Ocean database in the Pacific.

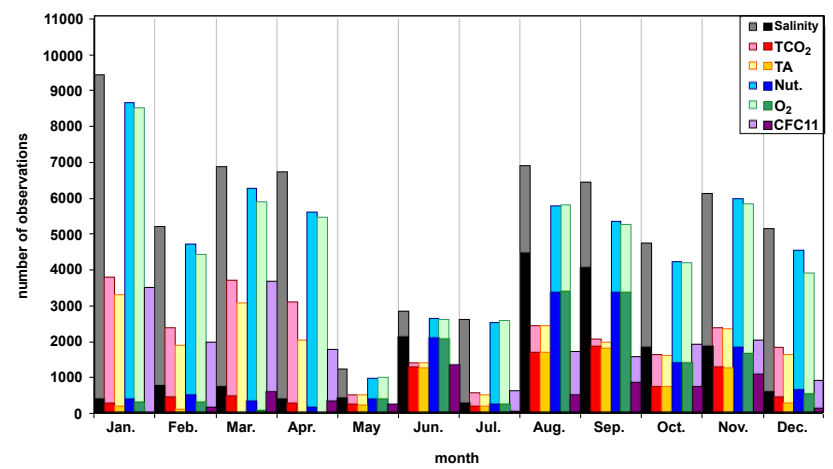

Figure 2. Distribution of Pacific sector Southern Ocean data by month for the primary measured parameters. Darker colors are for the GLODAP reference cruises. Lighter colors are for the CARINA cruises.

The oldest data are the GEOchemical SECtionS (GEOSECS) cruises run in 1973-1974. Only a few of the stations fell into the Southern Ocean. Most of the GLODAP cruises are from the early 1990s with a couple of cruises in the 1996-1998 timeframe (Table 1). The CARINA cruises extend the time frame up through 2006 , but also include a few cruises from the 1990s that were not available at the time of the GLODAP synthesis. The data are distributed throughout the year with the fewest samples from May through July (Fig. 2). The cruises during the Austral winter are very important for assessing the seasonal bias of the Southern Ocean dataset.

\section{Computational analysis approach}

Not all reported parameters from each cruise were evaluated. This work focuses on the evaluations of salinity, total carbon dioxide $\left(\mathrm{TCO}_{2}\right)$, total alkalinity (TA), nitrate, phosphate, silicate, and oxygen. A common quality control procedure was developed for all CARINA regions. It can be divided into three successive steps, starting with crossover analyses which consist in comparing deep measurements collected at nearby stations during two different cruises in order to detect any significant offset. The cruise-to-cruise differences (offsets) are then evaluated all together, parameter by parameter, in order to identify the cruises that could require an adjustment. Finally, the suggested adjustments are applied and crossover analyses of deep measurements are performed again in order to check the internal consistency of the dataset after correction. The quality control of the Southern Pacific Ocean dataset has been performed following these three steps, as for the other CARINA regions. Details about the common methodology can be found elsewhere (Tanhua et al., 2010). In this section only a brief description of the methods is given for the purpose of highlighting any divergence from the common procedure. 
Table 1. Description of cruises included in Pacific sector of the Southern Ocean analysis.

\begin{tabular}{|c|c|c|c|c|c|c|}
\hline expocode & Carina \# & \# stations & Date & Ship & Chief Scientist & Carbon PI \\
\hline 09AR19960822 & 33 & 71 & $8 / 22-9 / 21 / 1996$ & A. Australis & S. Rintoul & B. Tilbrook \\
\hline 09AR20011029 & 34 & 134 & $10 / 29-12 / 11 / 2001$ & A. Australis & S. Rintoul & B. Tilbrook, C. Sabine \\
\hline 09FA20010524 & 35 & 129 & $5 / 24 /-7 / 72001$ & Franklin & S. Wijffels & B. Tilbrook, C. Sabine \\
\hline 316 N20060130 & 70 & 101 & $1 / 30-3 / 14 / 2006$ & Knorr & B. Sloyan, L. Talley & \\
\hline 32MB19900222 & 80 & 64 & $2 / 24-4 / 12 / 1990$ & Baldridge & D. Wisegarver & M. Roberts, P. Murphy, R. Feely \\
\hline 33RR20050106 & 88 & 111 & $1 / 6-2 / 19 / 2005$ & R. Revelle & B. Sloyan, J. Swift & C. Sabine, A. Dickson \\
\hline $35 \mathrm{MF} 20030123$ & 104 & 10 & $1 / 23-2 / 17 / 2003$ & M.-Dufresne & N. Metzl & C. Lo Monaco \\
\hline 49HН19941213 & 110 & 11 & $12 / 13 / 1994-1 / 28 / 1995$ & Hakuho-Maru & K. Kawaguchi, M. Terazaki & M. Ishii \\
\hline 49HН20011208 & 111 & 18 & $12 / 8 / 2001-1 / 10 / 2002$ & Hakuho-Maru & M. Terazaki & M. Ishii \\
\hline 49NZ20030803 & 112 & 237 & $8 / 3-9 / 52003$ 9/9-10/16/2003 & Mirai & M. Fukasawa, S. Watanabe & A. Murata \\
\hline 61TG20020206 & 149 & 8 & $2 / 6-3 / 7 / 2002$ & Tangaroa & T. Odate & M. Ishii \\
\hline $61 \mathrm{TG} 20030217$ & 150 & 11 & $2 / 17-3 / 12 / 2003$ & Tangaroa & T. Odate & M. Ishii \\
\hline 320619960830 & & 4 & $8 / 30-9 / 24 / 1996$ & N. B. Palmer & R. Anderson & T. Takahashi \\
\hline 320619970113 & & 28 & $11 / 13 / 1997-1 / 17 / 1998$ & N. B. Palmer & J. Marra & T. Takahashi \\
\hline 320619970404 & & 17 & $4 / 4-5 / 12 / 1997$ & N. B. Palmer & H. Ducklow & F. Millero \\
\hline 09AR19910925 & & 26 & $9 / 25-10 / 27 / 1991$ & A. Australis & S. Rintoul & \\
\hline 09AR19930404 & & 62 & $4 / 4-5 / 9 / 1993$ & A. Australis & S. Rintoul & B. Tilbrook \\
\hline 09AR19941213 & & 106 & $12 / 13 / 1994-2 / 2 / 1995$ & A. Australis & S. Rintoul & B. Tilbrook \\
\hline 09FA19930624 & & 74 & $6 / 24-7 / 17 / 1993$ & Franklin & J. Church, S. Rintoul & \\
\hline 09FA19941112 & & 68 & $11 / 12-12 / 5 / 1994$ & Franklin & M. Tomczak & \\
\hline 316 N19920901 & & 52 & $9 / 1-9 / 15 / 1992$ & Knorr & D. Roemmich & J. Downing \\
\hline 316 N19921006 & & 127 & $10 / 6-11 / 25 / 1992$ & Knorr & J. Reid & T. Takahashi \\
\hline 316 N19921204 & & 106 & $12 / 4 / 1992-1 / 22 / 1993$ & Knorr & J. Swift & T. Takahashi \\
\hline $31 D S 19940126$ & & 193 & $1 / 26-4 / 27 / 1994$ & Discoverer & $\begin{array}{l}\text { J. Bullister, R. Feely, } \\
\text { G. Johnson, B. Taft }\end{array}$ & R. Feely, F. Millero \\
\hline $31 D S 19960105$ & & 182 & $1 / 5-3 / 10 / 1996$ & Discoverer & J. Bullister, R. Feely & $\begin{array}{l}\text { R. Feely, F. Millero, } \\
\text { R. Wanninkhof }\end{array}$ \\
\hline 31WT19910716 & & 97 & $7 / 16-8 / 25 / 1991$ & T. Washington & J. Swift & C. Goyet, T. Takahashi \\
\hline 33RR19971202 & & 19 & $12 / 2 / 1997-1 / 3 / 1998$ & R. Revelle & R. Barber & F. Millero \\
\hline 90KD19920214 & & 113 & $2 / 14-4 / 6 / 1992$ & A. Ioffe & M. Koshlyakov & T. Takahashi \\
\hline GEOSECS_PACIFIC & & 147 & $8 / 25 / 1973-6 / 9 / 1974$ & Melville & $\begin{array}{l}\text { H. Craig, W. Broecker, } \\
\text { T. Takahashi, D. Spencer, } \\
\text { R. Weiss, P. Biscaye, } \\
\text { J. Edmond, P. Brewer }\end{array}$ & $\begin{array}{l}\text { A. Bainbridge, A. Mantyla, } \\
\text { R. Williams, T. Takahashi, } \\
\text { R. Weiss }\end{array}$ \\
\hline
\end{tabular}

\subsection{Crossover analyses of uncorrected data}

The crossover analyses are objective comparisons of deep water data $(>1500 \mathrm{~m})$ collected in the same area during two different cruises. The station distribution was such that the definition of the crossover area was variable and defined subjectively on a case by case basis: the area considered by default is a circle of $222 \mathrm{~km}$ radius around a sampling station, which can be decreased in frontal regions or increased in homogeneous deep waters. In some cases, when the crossover area covers different hydrological regions (e.g. repeated cruise lines), the data were separated into one or more clusters and analyzed as separate crossovers. The mean offset between two cruises is estimated by comparing the mean profiles generated for each cruise by averaging deep measurements found in a crossover area (or cluster) along isopycnal surfaces, as described by Tanhua et al. (2010). Crossover plots and statistics were first generated manually in order to allow the operator to change the settings when appropriate. Then, similar analyses were performed using an automated (objective) method (Running cluster, see Tanhua et al., 2010), but because it requires at least three stations per cruise to produce statistics not all crossovers could be eval- uated this way. It should be noted also that most crossovers were evaluated using the manual routine, but not all because of the addition of more cruise data after the initial manual checks. Nevertheless it should be appreciated that the results of the manual and automatic routines are generally in good agreement (see Fig. 2 in Tanhua et al., 2010). All the manually and automatically generated crossover plots are available on the interactive CARINA website (http://cdiac.ornl. gov/oceans/CARINA/Carina_inv.html, Tanhua et al., 2010).

The 29 cruises that cover the South Pacific Ocean had a total of 57 crossovers. Crossovers could be used to evaluate all CARINA cruises for at least one parameter, but there were two GLODAP cruises (320619970113, 09FA19941112) that did not have sufficient crossovers to evaluate data quality. For those crossovers that included only one or two stations for one or the two cruises, the plots and statistics were generated manually in a slightly different way as the common method in the sense that the statistics produced are not comparable: for crossovers having at least three stations per cruise the error associated with the mean offset reflects the standard deviation around each cruise's mean profile, whereas in the other case the error is given by the standard deviation of the mean difference between the two profiles. 


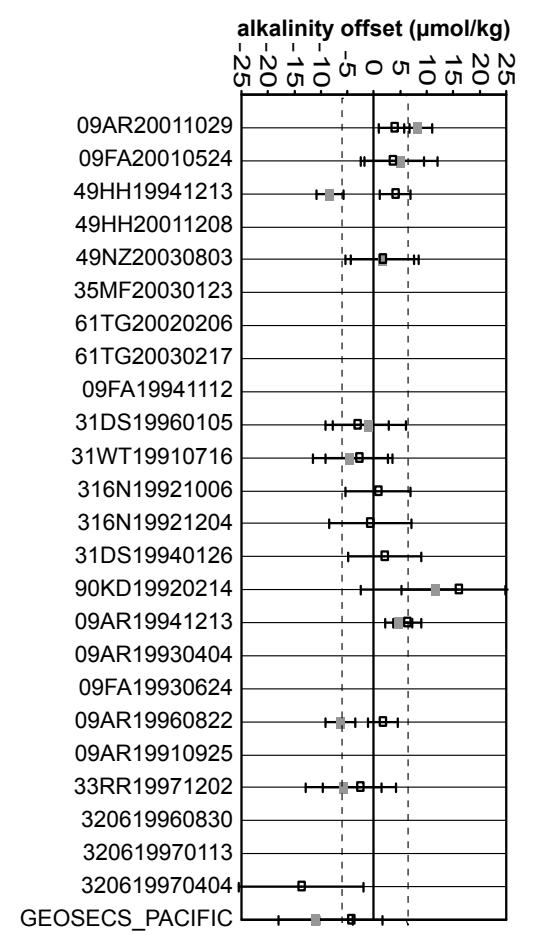

$\mathrm{TCO}_{2}$ offset $(\mu \mathrm{mol} / \mathrm{kg})$
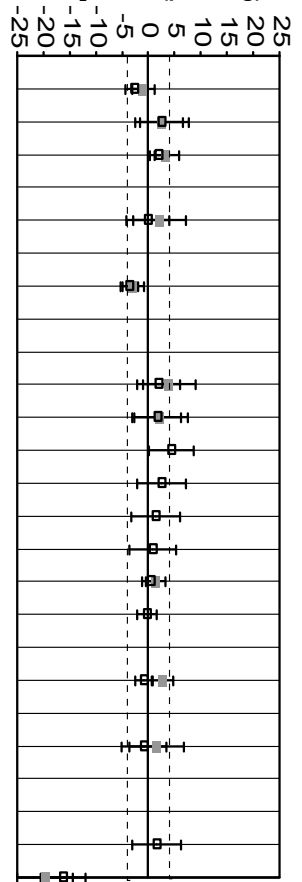

salinity offset * 1000
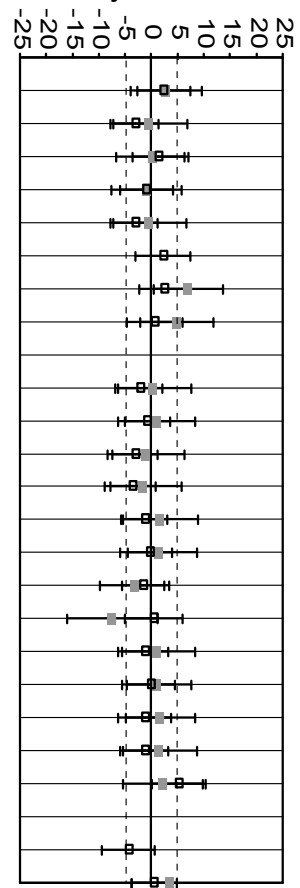

Figure 3. Results of initial inversion (grey boxes) of crossover results and for the final inversion after cruise adjustments were made (black squares) for those parameters with additive corrections. Error bars indicate one standard deviation of the inverted offset. The dashed lines indicate the minimum offsets required for an adjustment to be proposed $\left(0.005\right.$ for salinity, $4 \mu \mathrm{mol} \mathrm{kg}^{-1}$ for $\mathrm{TCO}_{2}, 6 \mu \mathrm{mol} \mathrm{kg}^{-1}$ for alkalinity).

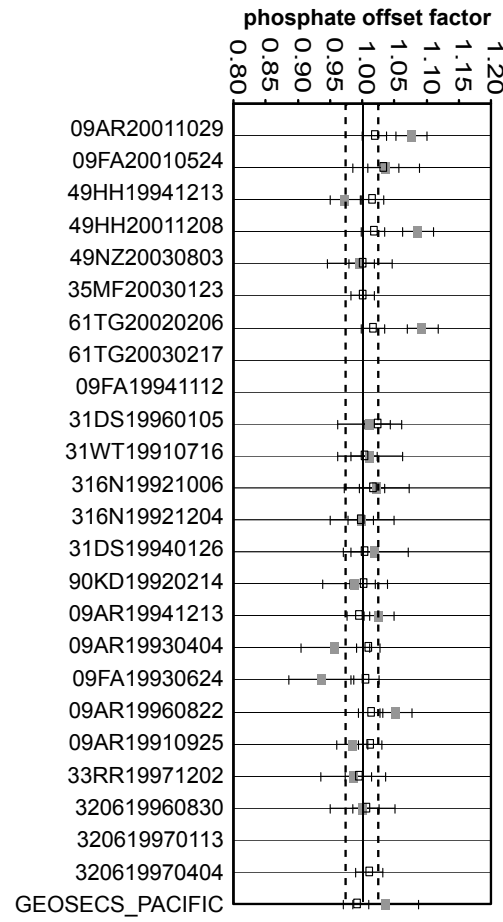

nitrate offset factor

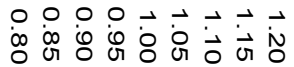

silicate offset factor

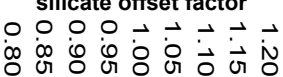

oxygen offset factor

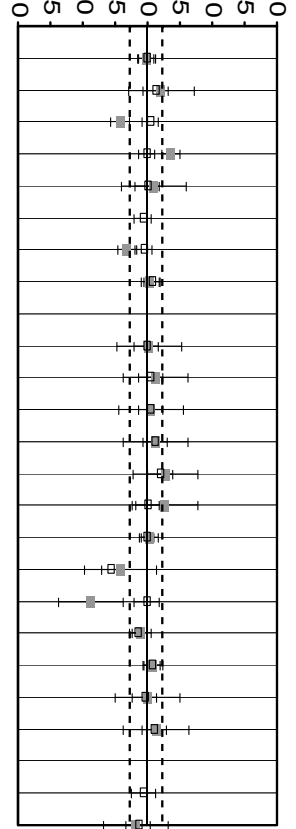

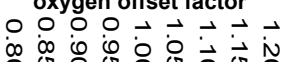
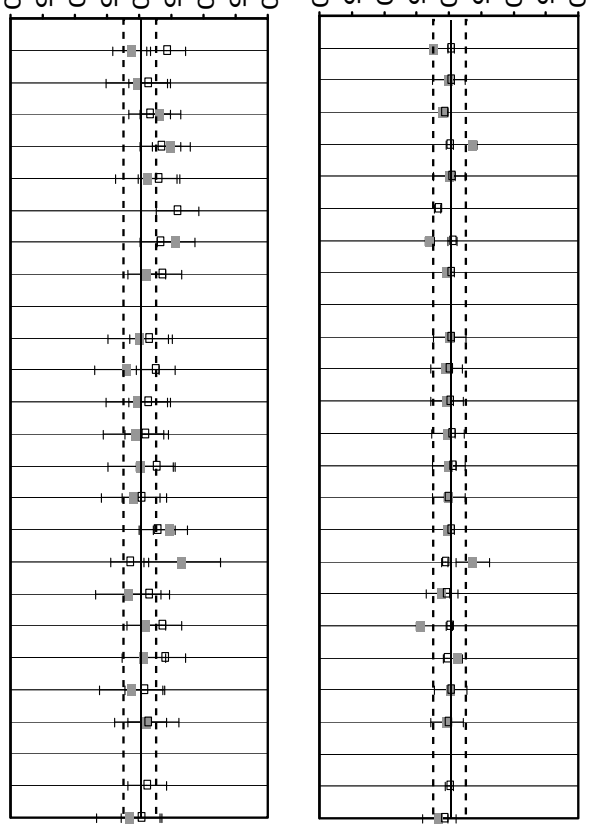

Figure 4. Results of initial inversion (grey boxes) of crossover results and for the final inversion after cruise adjustments were made (black squares) for those parameters with multiplicative corrections. Error bars indicate one standard deviation of the inverted offset. The dashed lines indicate the minimum offsets required for an adjustment to be proposed ( $2 \%$ for nutrients and $1 \%$ for oxygen). 
Table 2. Proposed adjustments for cruises included in Pacific sector of the Southern Ocean analysis. A “-999” indicates that the parameter was not reported and a " -888 " means that the parameter was measured but not evaluated.

\begin{tabular}{|c|c|c|c|c|c|c|c|c|c|}
\hline expocode & Carina \# & cruise line & Salinity [+] & $\mathrm{TCO} 2[+]$ & Alkalinity [+] & Nitrate $[\mathrm{x}]$ & Phosphate $[\mathrm{x}]$ & Silicate $[\mathrm{x}]$ & Oxygen $[\mathrm{x}]$ \\
\hline 09AR20011029 & 34 & SR3 & 0 & 0 & 0 & 1 & 1.03 & 0.98 & 0.98 \\
\hline 09FA20010524 & 35 & P15S & 0 & 0 & 0 & 1 & 1 & 1 & 1 \\
\hline $32 \mathrm{MB} 19900222$ & 80 & P15S & 0 & 6 & -999 & -888 & -888 & -888 & -888 \\
\hline 33RR20050106 & 88 & $\mathrm{P} 16$ & -888 & -888 & -888 & 1 & 1 & -888 & -888 \\
\hline $35 \mathrm{MF} 20030123$ & 104 & SR3 & -0.011 & 0 & 0 & 1 & 1.1 & 1.14 & 1 \\
\hline 49NZ20030803 & 112 & P06 & 0 & 0 & 0 & 1 & 1 & 1 & 1 \\
\hline 61TG20020206 & 149 & SR3 & 0 & 0 & -999 & 0.98 & 1.05 & 1.05 & 0.97 \\
\hline 61TG20030217 & 150 & SR3 & 0.005 & -999 & -999 & 1 & -999 & 1 & 1 \\
\hline 320619960830 & & NBP96_4 & 0 & -888 & -999 & 1 & 1 & 1 & 1 \\
\hline 320619970113 & & NBP97_1 & -888 & -888 & -999 & -888 & -888 & -888 & -888 \\
\hline 320619970404 & & NBP97_3 & 0 & 0 & -999 & 1 & 1 & 1 & 1 \\
\hline 09AR19910925 & & SR3 & 0 & -999 & -999 & 1 & 0.93 & 1 & 1.02 \\
\hline 09AR19930404 & & P11A & -0.01 & 0 & -999 & 1 & 0.98 & 1.07 & 1.03 \\
\hline 09AR19941213 & & S3 S4 & 0 & 0 & 0 & 1 & 1 & 1.03 & 1 \\
\hline 09FA19930624 & & P11S & 0 & -999 & -999 & 0.92 & 0.95 & 0.98 & 0.99 \\
\hline 09FA19941112 & & S05 & -888 & -999 & -999 & -888 & -888 & -888 & -888 \\
\hline 316 N19920901 & & $\mathrm{P} 14 \mathrm{C}$ & 0 & -888 & -888 & 1 & 1 & 0.98 & 0.99 \\
\hline 316 N19921006 & & P16A 17A & 0 & 0 & 0 & 1 & 1 & 1 & 1 \\
\hline $316 \mathrm{~N} 19921204$ & & P17E 19S & 0 & 0 & 0 & 1 & 1 & 1 & 1 \\
\hline 31DS19940126 & & $\mathrm{P} 18$ & 0 & 0 & 0 & 1 & 1 & 1 & 1 \\
\hline 31DS19960105 & & P14S 15S & 0 & 0 & 0 & 1 & 1 & 1 & 1 \\
\hline 31WT19910716 & & P16S 17S & 0 & 0 & 0 & 1 & 1 & 0.97 & 1 \\
\hline 33RR19971202 & & KIWI-7 & 0 & 0 & 0 & 1 & 1 & 1 & 1 \\
\hline 90KD19920214 & & $\mathrm{S} 4 \mathrm{P}$ & 0 & 0 & -888 & 1.02 & 1 & 1 & 1 \\
\hline GEOSECS_PACIFIC & & Geosecs & 0 & -23 & -12 & 1 & 1.03 & 1 & 1 \\
\hline
\end{tabular}

\subsection{Identification of cruises to be adjusted}

A crossover results in an offset for the cruise of interest (cruise A) relative to another cruise (cruise B), i.e. offset $=$ cruise $\mathrm{A} /$ cruise $\mathrm{B}$. Thus if the offset is less than unity, the values from cruise A are lower than those from cruise B. Similarly, if the average of all crossovers for cruise A is less than unity, the values from cruise A are lower than the values from other cruises in the area. The information deduced from crossover analyses can be synthesized by the mean of an inverse method in order to determine the adjustments required for improving coherence of the dataset (Johnson et al., 2001). Results from the automatically generated crossovers were used to perform a global Southern Ocean inversion, i.e. including the Atlantic and Indian sectors (Hoppema et al., 2009; Lo Monaco et al., 2010), as described in Tanhua et al. (2010). The inversion process results in a suggestion for a correction to cruise $\mathrm{A}$. If cruise $\mathrm{A}$ is lower than other cruises in the area, the correction will most likely be larger than unity, i.e. the data from cruise A will have to be corrected upwards for consistency with other cruises. When we discuss adjustment, we refer to the correction that was actually applied to the data.
Johnson et al. (2001) presented three types of inversions: Simple Least Squares (SLSQ), Weighted Least Squares (WLSQ), and Weighted Dampened Least Squares (WDLSQ). The first method being considered as too simple for the CARINA dataset, only the two other methods were used. The adjustments proposed by these two inversions were evaluated by comparison with the information deduced from manually generated crossovers (results not shown). This showed a better agreement with results from the WDLSQ inversion for which a priori assumptions on the quality of the data are made, compared to the slightly less complex WLSQ method that uses the standard deviation associated with each crossover to weight the inversion. Consequently, only the results from the WDLSQ inversion were considered for further analyses. Figures 3 and 4 show the results of the WDLSQ inversion for the Pacific sector cruises based on the crossovers of the initial cruise data and from an inversion of the data after adjustments were made. Note that the offsets for salinity, $\mathrm{TCO}_{2}$ and alkalinity are additive (i.e. add the proposed inversion result to the originally reported value). The other parameters are multiplicative offsets (i.e. multiply the proposed inversion value by the originally reported value). The advantage of using an inversion 
to identify the cruises that could require an adjustment is that the whole Southern Ocean dataset was treated at once. A major problem is that because the inversion is performed from automatically generated crossovers it does not include crossovers with less than three stations per cruise.

Corrections to be applied to the CARINA dataset were determined by comparing deductions from the manual crossovers with the results of the WDLSQ inversion when possible. Parameters were evaluated cruise by cruise, and only adjustments above a defined threshold were considered for correction $\left(0.005\right.$ for salinity, $4 \mu \mathrm{mol} \mathrm{kg}{ }^{-1}$ for $\mathrm{TCO}_{2}$, $6 \mu \mathrm{mol} \mathrm{kg}{ }^{-1}$ for alkalinity, $2 \%$ for nutrients and $1 \%$ for oxygen). In a few cases when the crossover fits appeared to be of poor quality or when there was contradictory evidence for an adjustment, a decision was made not to adjust the data ( -888 in Table 2).

\subsection{Crossover analyses after data adjustment}

The last step consists in evaluating the improvement in data coherence after the suggested adjustments had been applied. This was done by performing new crossover analyses of deep data after adjustment using the automatic running cluster routine. The results are compared to those obtained before data adjustment again using the inversion method as above (see Figs. 3 and 4). In some few cases there was a need for modifying the adjustment, so they were only considered final after this last check.

\section{Results and recommendations}

Table 2 summarizes the adjustments recommended for the CARINA and GLODAP cruises. Figures 5 and 6 show the same information graphically. Note that since the offsets reported above for salinity, $\mathrm{TCO}_{2}$ and alkalinity were additive, the corrections for these parameters are also additive (i.e. add the proposed correction to the originally reported value). The other parameters are multiplicative adjustments (i.e. multiply the proposed correction by the originally reported value). Below, we discuss the adjustments for each of the parameters examined.

\subsection{Salinity}

Salinity was measured on all the cruises assembled in the CARINA-GLODAP merged dataset. Salinity was generally determined on discrete samples collected from Niskin type bottles and measured using a salinometer. These samples routinely have a high accuracy due to widely accepted use of international standards (IAPSO seawater). On samples where discrete salinity values were not reported, the salinity was taken from the electronic Conductivity-TemperatureDepth (CTD) device. Since these instruments are calibrated against the discrete samples, they are also very reliable.
Three cruises were not evaluated (316N20060130, 320619970113, 09FA19941112) due to lack of crossovers or other complications. Good agreement $(< \pm 0.005)$ from the crossover analyses was obtained for all but three the cruises. CARINA cruise 61TG20030217 south of Tasmania had an offset of -0.005 based on 10 crossovers and 35MF20030123 had an offset of 0.011 based on 9 crossovers. One GLODAP cruise, 09AR19930404, had 9 crossovers indicating a correction of -0.01 which was applied to the data. This is similar to the correction of -0.0065 determined during the GLODAP analysis. Figure 3 shows that after correction, all but one cruise were within the 0.005 crossover envelope.

\section{$4.2 \mathrm{TCO}_{2}$}

$\mathrm{TCO}_{2}$ was measured on all but 5 of the cruises (Table 2). For cruises conducted before the use of Certified Reference material (CRM, introduced by A. G. Dickson, Scripps Institution of Oceanography, in 1991), such as GEOSECS, a significant offset is sometimes observed. We propose a correction of $-23 \mu \mathrm{mol} \mathrm{kg}{ }^{-1}$ for the GEOSECS Pacific $\mathrm{TCO}_{2}$ data. This is slightly smaller than previously proposed adjustments to the GEOSECS Pacific data (Takahashi et al., 1982; Sabine et al., 2004b, Takahashi, personal communication) but this work only considers relatively few stations in the southern portion of the Pacific. Only one CARINA cruise had an adjustment $\left(32 \mathrm{MB} 19900222=6 \mu \mathrm{mol} \mathrm{kg}{ }^{-1}\right)$. Four cruises were not evaluated (49HH20011208, 320619960830, 320619970113, 316 N19920901) due to lack of crossovers or other complications. Figure 3 shows that after adjustment, all cruises were within the crossover envelope of $4 \mu \mathrm{mol} \mathrm{kg}{ }^{-1}$.

\subsection{Total alkalinity}

Alkalinity was measured on 17 of the 29 cruises. Two of the 17 cruises (316N19920901, 90KD19920214) could not be evaluated because of lack of crossovers. CRMs were used for alkalinity measurements during most of WOCE and post-WOCE cruises, but because most of the TA data was collected prior to their use, offsets between cruises are expected. Thirteen cruises had no recommended adjustments, but an adjustment was applied to one CARINA cruise (49HH19941213 $\left.=-16.1 \mu \mathrm{mol} \mathrm{kg}{ }^{-1}\right)$. No GLODAP cruises had proposed corrections in agreement with the GLODAP analysis. The crossover analyses indicated that the Pacific GEOSECS alkalinity data needed a correction of $-12 \mu \mathrm{mol} \mathrm{kg}{ }^{-1}$. Figure 3 shows that after adjustment, a couple of cruises remained outside the crossover envelope of $6 \mu \mathrm{mol} \mathrm{kg}{ }^{-1}$, but manual examination of the crossover results indicated that the corrections proposed by the inversion for these cruises could not be justified. 


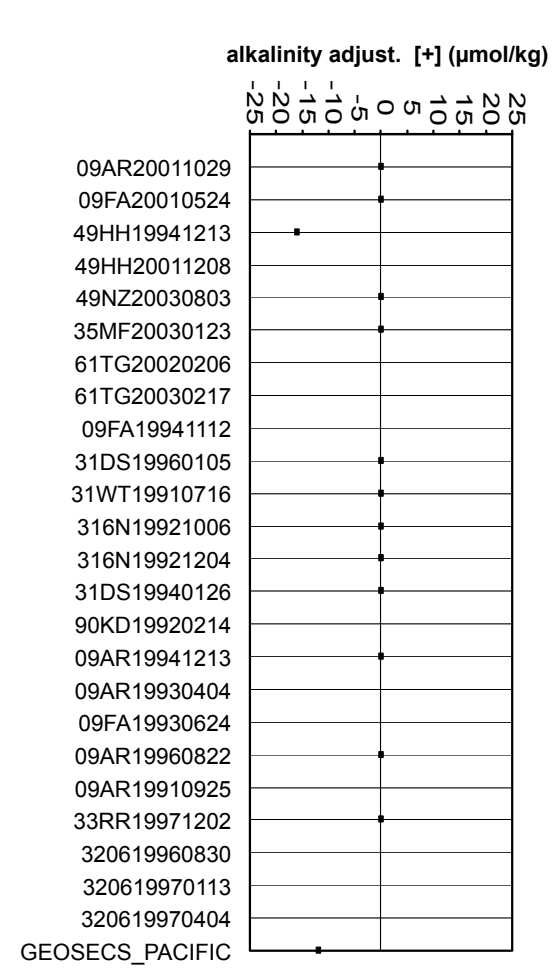

salinity adjustments [+]

$\mathrm{TCO}_{2}$ adjust. [+] ( $\left.\mu \mathrm{mol} / \mathrm{kg}\right)$

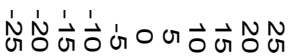

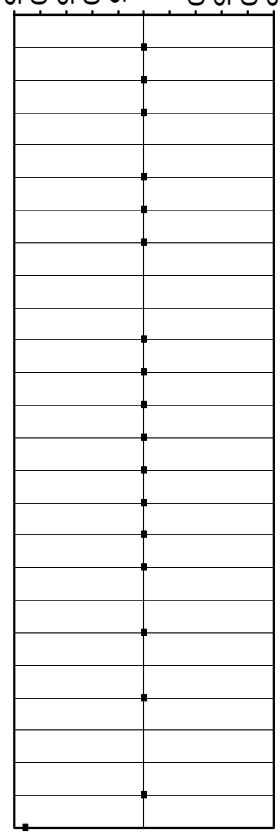

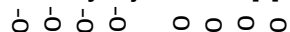

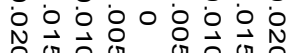

u o o 0 u

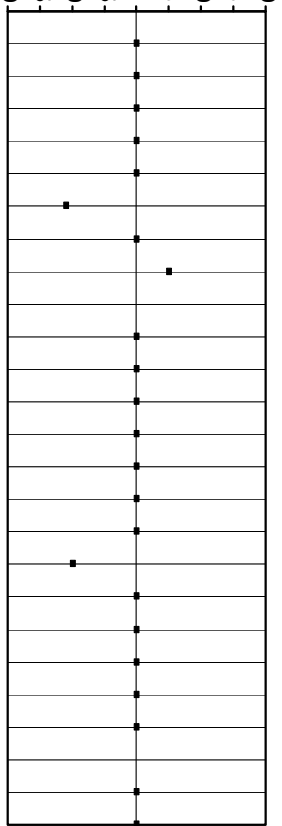

Figure 5. Additive adjustments made to alkalinity, $\mathrm{TCO}_{2}$ and salinity data.

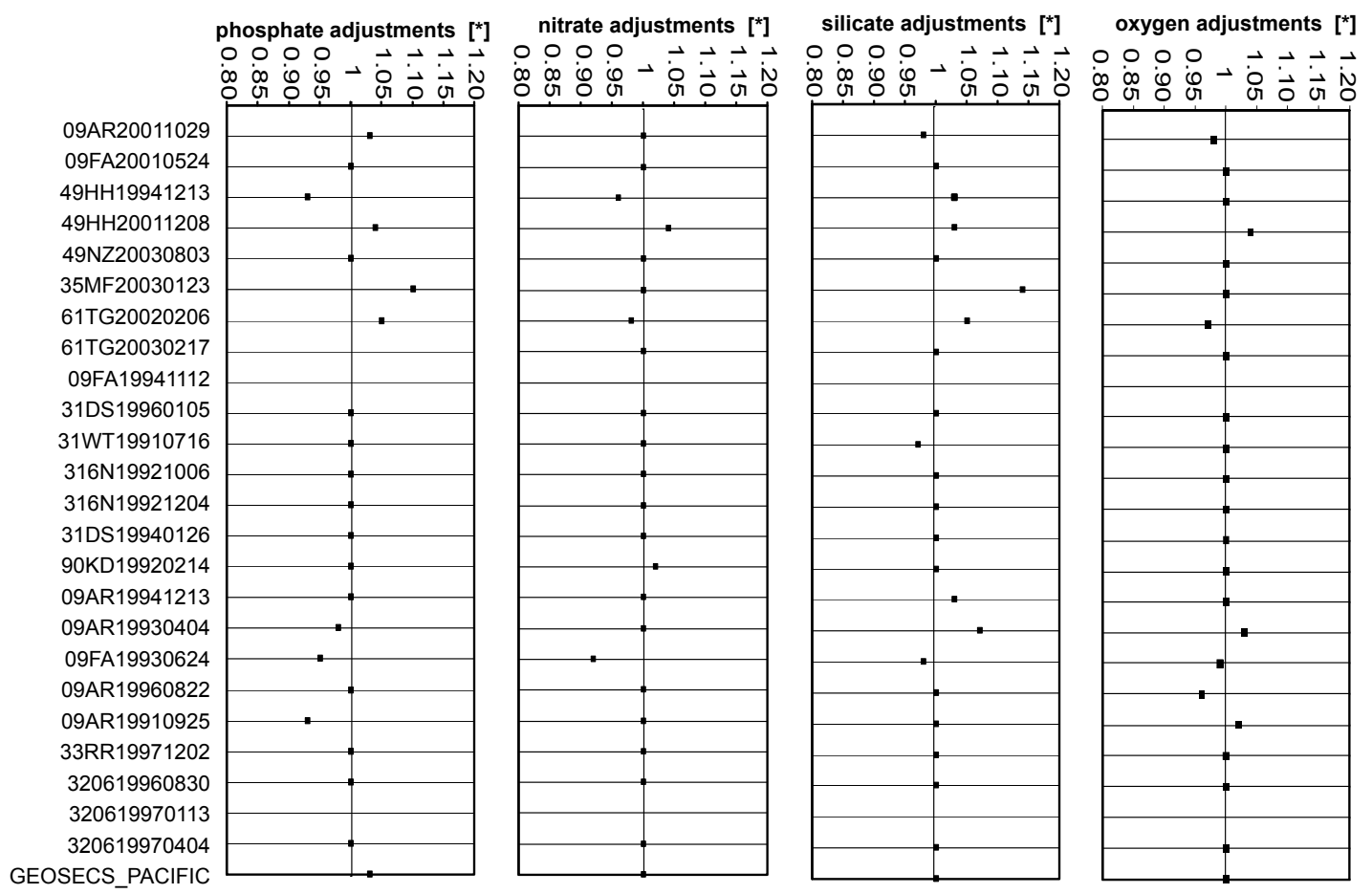

Figure 6. Multiplicative adjustments made to nutrient and oxygen data. 


\subsection{Nutrients}

Nitrate, phosphate, and silicate were measured on all cruises. No international standard existed for nutrients measurements at the time of these cruises, therefore offsets were detected in several crossovers. Four of the cruises could not be evaluated due to lack of crossovers (316N20060130, 320619970113, 09FA19941112, 32MB19900222). Nitrate corrections were suggested for 5 cruises: 49HH19941213 $=0.96$, 49HH20011208 $=1.04, \quad 61 \mathrm{TG} 20020206=0.98$, 90KD19920214=1.02, 09FA19930624=0.92. Phosphate corrections ranging from 0.93 to 1.1 were suggested for nine of the cruises (see Table 2 for details). Silicate corrections ranging from 0.97 to 1.14 were suggested for ten cruises. The suggested corrections for the GLODAP cruises were in reasonable agreement with the GLODAP correction factors as determined by Gouretski and Jancke (2001), but the GLODAP data were not adjusted here. The corrections recommended for the CARINA cruises were applied to the final CARINA dataset. Figure 4 show that after adjustment, almost all the cruises are within the acceptable $2 \%$ crossover envelope.

\subsection{Oxygen}

Oxygen was measured on all cruises. International standards exist for oxygen measurements, but they are not commonly used. Therefore, offsets were detected in several crossovers. Four of the cruises could not be evaluated due to lack of crossovers (316N20060130, 320619970113, 09FA19941112, 32MB19900222). Corrections ranging from 0.96 to 1.04 were suggested for nine of the cruises. See Table 2 for details. The proposed corrections for the GLODAP cruises were in reasonable agreement with the GLODAP correction factors. Figure 4 shows that after adjustment, almost all the cruises are within the acceptable $1 \%$ crossover envelope.

\section{Concluding remarks}

The inversion results performed before and after adjustment show that the adjusted data set is much more internally consistent than the original cruise results. This improvement can be quantified by considering the weighted mean (WM) of the inversion results. The WM was calculated for each parameter using the absolute value of the offset $(D)$ of $L$ crossovers with the uncertainty $(\sigma)$ :

$\mathrm{WM}=\frac{\sum_{i=1}^{L} D(i) /(\sigma(i))^{2}}{\sum_{i=1}^{L} 1 /(\sigma(i))^{2}}$

Based on this analysis the internal consistency of the $\mathrm{TCO}_{2}$ data improved from an uncertainty of $7.4 \mu \mathrm{mol} \mathrm{kg}{ }^{-1}$ for the uncorrected data to about $2.3 \mu \mathrm{mol} \mathrm{kg}{ }^{-1}$ after the corrections were applied. The alkalinity data improved from an uncer-

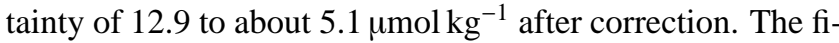
nal salinity, nutrient and oxygen data have an estimated consistency of: 0.002 for salinity, $0.8 \%$ for oxygen, $1.1 \%$ for nitrate, $1.3 \%$ for phosphate and $1.2 \%$ for silicate. Since The core cruises are believed to have accurate measurements and the majority of cruises did not indicate a meaningful difference relative to the core cruises, we take these internal consistency estimates $t \mathrm{o}$ also represent estimated accuracies for the data.

The CARINA database consist of essentially two parts: The first part is the individual cruise files where all the data that was measured, and their flags, are stored. These files are in WHP exchange format where the first lines consist of the condensed metadata. There are no calculated nor any interpolated values in the individual cruise files, and no adjustments have been applied to the values. In many cases there are more reported parameters in the individual cruise files than have been included in the secondary quality control analysis presented here (e.g. ${ }^{14} \mathrm{C},{ }^{13} \mathrm{C}, \mathrm{SF}_{6}$ ). The second part of the CARINA database is the merged data. There are three merged data files, one of which is the Southern Ocean data. This file includes: Interpolated values for nutrient, oxygen, salinity, $\mathrm{TCO}_{2}$ and alkalinity if those data are missing and if interpolation can be made according to criteria described in Key et al. (2010); Calculated carbon parameters (i.e. if $\mathrm{TCO}_{2}$ and alkalinity was measured, $\mathrm{pH}$ and $p \mathrm{CO}_{2}$ is calculated). Calculated and interpolated values have the quality flag " 0 ". All the values in the merged data file have been adjusted according to the values in Table 2 .

Acknowledgements. This work has been done and funded as part of the EU project CARBOCEAN (no. 511176; GOCE) and by the NOAA Climate Program Office. Additional support from the International Ocean Carbon Coordination Project IOCCP (Maria Hood) and the Hanse Institute for Advanced Study (HWK Delmenhorst, Germany) was gratefully accepted. Without the dedication of all investigators and analysts who performed measurements, sometimes under adverse conditions, and contributed their data to the CARINA data base, this project would not have been possible. This is PMEL publication number 3460.

Edited by: T. Tanhua

\section{References}

Gouretski, V. V. and Jancke, K.: Systematic errors as the cause for an apparent deep water property variability: global analysis of the WOCE and historical hydrographic data, Prog. Oceanogr., 48(4), 337-402, 2001.

Hoppema, M., Velo, A., van Heuven, S., Tanhua, T., Key, R. M., Lin, X., Bakker, D. C. E., Perez, F. F., Ríos, A. F., Lo Monaco, C., Sabine, C. L., Álvarez, M., and Bellerby, R. G. J.: Consistency of cruise data of the CARINA database in the Atlantic sector of the Southern Ocean, Earth Syst. Sci. Data, 1, 63-75, doi:10.5194/essd-1-63-2009, 2009. 
Johnson, G. C., Robbins, P. E., and Hufford, G. E.: Systematic adjustments of hydrographic sections for internal consistency, J. Atmos. Ocean. Tech., 18(7), 1234-1244, 2001.

Key, R. M., Kozyr, A., Sabine, C. L., Lee, K., Wanninkhof, K., Bullister, J. L., Feely, R. A., Millero, F. J., Mordy, C., and Peng, T. H.: A global ocean carbon climatology: Results from Global Data Analysis Project (GLODAP), Global Biogeochem. Cy., 18, GB4031, doi:10.1029/2004GB002247, 2004.

Key, R. M., Tanhua, T., Olsen, A., Hoppema, M., Jutterström, S., Schirnick, C., van Heuven, S., Kozyr, A., Lin, X., Velo, A., Wallace, D. W. R., and Mintrop, L.: The CARINA data synthesis project: introduction and overview, Earth Syst. Sci. Data, 2, 105121, doi:10.5194/essd-2-105-2010, 2010.

Lo Monaco, C., Álvarez, M., Key, R. M., Lin, X., Tanhua, T., Tilbrook, B., Bakker, D. C. E., van Heuven, S., Hoppema, M., Metzl, N., Ríos, A. F., Sabine, C. L., and Velo, A.: Assessing the internal consistency of the CARINA database in the Indian sector of the Southern Ocean, Earth Syst. Sci. Data, 2, 51-70, doi:10.5194/essd-2-51-2010, 2010.

Sabine, C. L., Feely, R. A., Gruber, N., Key, R. M., Lee, K., Bullister, J. L., Wanninkhof, R., Wong, C. S., Wallace, D. W. R., Tilbrook, B., Millero, F. J., Peng, T.-H., Kozyr, A., Ono, T., and Rios, A. F.: The oceanic sink for anthropogenic $\mathrm{CO}_{2}$, Science, 305, 367-371, 2004a.
Sabine, C. L., Feely, R. A., Watanabe, Y. W., and Lamb, M. F.: Temporal evolution of the north Pacific $\mathrm{CO}_{2}$ uptake rate, J. Oceanogr., 60(1), 5-15, 2004b.

Sabine, C. L., Key, R. M., Kozyr, A., Feely, R. A., Wanninkhof, R., Millero, F. J., Peng, T.-H., Bullister, J. L., and Lee, K.: Global Ocean Data Analysis Project: Results and Data, ORNL/CDIAC145, NDP-083, Carbon Dioxide Information Analysis Center, Oak Ridge National Laboratory, US Department of Energy, Oak Ridge, Tennessee, 110 pp., 2005.

Takahashi, T., Williams, R. T., and Bos, D. L.: Carbonate chemistry, in: GEOSECS Pacific Expedition, Vol. 3, Hydrographic Data 1973-1974, edited by: Broecker, W. S., Spencer, D. W., and Craig, H., National Science Foundation, Washington, D.C., 77-83, 1982.

Tanhua, T., van Heuven, S., Key, R. M., Velo, A., Olsen, A., and Schirnick, C.: Quality control procedures and methods of the CARINA database, Earth Syst. Sci. Data, 2, 35-49, doi:10.5194/essd-2-35-2010, 2010. 